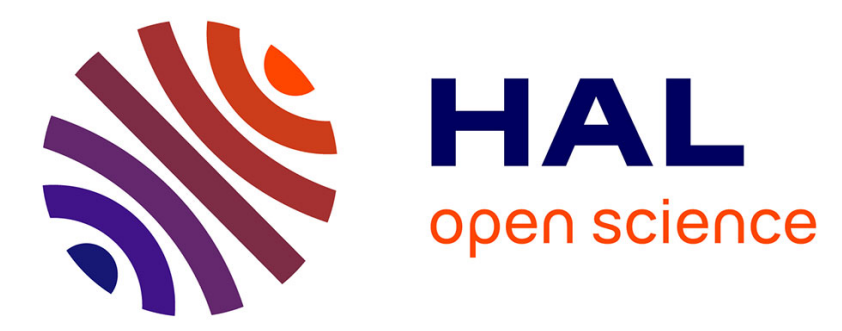

\title{
An Evolutionary Perspective on Ethylene Sensing in Microorganisms
}

\author{
Nicolas Papon, Brad Binder
}

\section{To cite this version:}

Nicolas Papon, Brad Binder. An Evolutionary Perspective on Ethylene Sensing in Microorganisms. Trends in Microbiology, 2019, 27 (3), pp.193-196. 10.1016/j.tim.2018.12.002 . hal-02483144

\section{HAL Id: hal-02483144 \\ https://univ-angers.hal.science/hal-02483144}

Submitted on 21 Oct 2021

HAL is a multi-disciplinary open access archive for the deposit and dissemination of scientific research documents, whether they are published or not. The documents may come from teaching and research institutions in France or abroad, or from public or private research centers.
L'archive ouverte pluridisciplinaire HAL, est destinée au dépôt et à la diffusion de documents scientifiques de niveau recherche, publiés ou non, émanant des établissements d'enseignement et de recherche français ou étrangers, des laboratoires publics ou privés.

\section{다(1) $\$$}

Distributed under a Creative Commons Attribution - NonCommercial| 4.0 International 


\title{
Forum
}

\section{An Evolutionary Perspective on Ethylene Sensing in Microorganisms}

\author{
Nicolas Papon ${ }^{1, *}$ and Brad M. Binder ${ }^{2}$ \\ ${ }^{1}$ Groupe d'Etude des Interactions Hôte-Pathogène, GEIHP, EA 3142, SFR ICAT 4208, UNIV Angers, UNIV Brest, Institut de Biologie en \\ Santé, IRIS, CHU Angers, France \\ ${ }^{2}$ Department of Biochemistry, Cellular, and Molecular Biology, University of Tennessee, Knoxville, Tennessee, USA \\ *Correspondence: nicolas.papon@univ-angers.fr (N. Papon) \\ Keywords : ethylene, receptors, phytohormones, bacteria, fungi, amoebae
}

Ethylene is a gas and a plant hormone with wide ranging effects and a well-defined signaling pathway. The recent identification of ethylene receptors in various microorganisms provides new insights into the early propagation of the ethylene signaling pathway in the course of evolution.

\section{The roles of ethylene: in a historical way a plant story}

Ethylene is a gas naturally produced by plants, algae, fungi, and bacteria [1]. The role of ethylene was first documented in plants where it acts primarily as a hormone that regulates many aspects of development such as seed germination, leaf senescence, and fruit ripening. It also orchestrates plant defenses against micro-organisms and animals, the establishment of symbiosis, and responses to abiotic stresses such as high salt, drought, flooding, and pollutants. The effects of ethylene on non-plant species is less studied and the data on this issue remains more fragmentary [2].

\section{Ethylene signaling in plants and Synechocystis}

Ethylene is produced by many microbes and is also abiotically generated from incomplete combustion and from light interacting with dissolved organics [1]. Thus, it is likely that ethylene was broadly present on ancient earth leading to the idea that this simple gas was co-opted as a signaling molecule by early organisms. However, most studies on ethylene signaling focus on plants and the first ethylene receptor (ETR) was discovered in the model plant Arabidopsis thaliana [3]. ETRs of higher plants are related to the histidine kinase superfamily (Fig. 1A). Histidine kinases are relatively rare in eukaryotes and autophosphorylation of plant ETRs and phosphotransfer to other effectors are not critical for ethylene signaling. Upon binding to the dimerized ETR, ethylene negatively regulates a cell signaling pathway involving downstream mediators including the raf-like protein kinase Constitutive Triple Response 1 (CTR1), the endoplasmic reticulum-localized protein Ethylene Insensitive 2 (EIN2), and the EIN3 and EIN3-Like (EIL) transcription factors [4]. This land plant-type ethylene signaling pathway likely occurs in the green lineage from unicellular algae since ETR homologs are detected in some chlorophyte genomes (e.g. Coelastrella and Coccomyxa sp.).

It has long been supposed that the above-described canonical ETR-mediated signaling pathways were restricted to terrestrial plants [5], although, a putative ETR, slr1212, was identified almost 20 years ago in the cyanobacterium Synechocystis sp. [6]. This led to the idea that plants acquired ETRs from the cyanobacterium that gave rise to chloroplasts and subsequent gene transfer to the host cell. However, it was only recently that this protein was shown to be a bona 
fide ETR, as well as photoreceptor, that governs various processes underlying cell motility $[7,8]$ (Fig. 1B).

From a structural point of view, it is important to highlight ethylene sensing through ETRs occurs by the interaction of the gaseous molecule with the ethylene binding domain (EtBD) located at the N-terminus of the receptors. The EtBD consists of three hydrophobic transmembrane helices harboring seven conserved amino-acids required for ethylene binding [9] (Fig. 1C). This structural uniqueness has allowed for a more thorough search over the last few years for ETR homologs in additional prokaryotic and eukaryotic lineages.

\section{Recent phylogenomic analyses revealed the presence of ethylene receptors in microorganisms}

As mentioned above, ETRs were first identified in plants [3]. Later, the sequencing of the Synechocystis genome revealed it also contained a putative ETR [6]. More recent studies have identified plant ETR homologs in over 100 bacterial species consisting predominantly of proteobacteria and cyanobacteria [7,9] (Fig. 1C). Most of these prokaryotic ETRs display domain arrangements similar to those observed in plants (histidine kinase-like), but, interestingly, a few show atypical features with simplified or more complex structures and alternative output domains (Fig. 1C). This suggests that some bacterial ETRs (i) may integrate multiple input signals in addition to ethylene and (ii) have diverse biochemical outputs.

ETR homologs were also recently identified in various non-plant eukaryotic clades. Several fungal genomes were shown to encode proteins that strongly resemble the domain arrangement of higher plant ETRs [10] (Fig. 1C). Specifically, these ETR homologs were found in "lower" fungi (so called Early Diverging Fungi") that are known to behave as plant symbionts, as well as in species that colonize decaying plant material. Emblematic of these are Glomeromycotina (i.e. Rhizophagus irregularis, Fig. 1C). These fungi are part of a symbiotic relationship (arbuscular mycorrhizae) along with plant roots, and ethylene has been demonstrated to be involved in this interaction. The presence of ETRs in this particular group of fungi deeply-associated to plants provides new insight into the hormonal communication that may operate in these symbioses. In addition, homologous sequences of ETRs are predicted to be present in several other early diverging fungi that colonize leaf litter, twigs, decaying fruit, and soil. It is also interesting to observe ETR homologs in the aquatic species Allomyces macrogynus (Chytridiomycota) and in its obligate parasite Rozella allomyces (Cryptomycota) (Fig. 1C). One could speculate that ethylene acts as a communication molecule between these two aquatic fungi. In sum, based on the distribution of ETR homologs in early diverging fungi, it is tempting to hypothesize that ethylene sensing has been co-opted by "lower" fungi for orchestrating interactions in several plant-fungi or fungi-fungi biotic systems.

A recent phylogenomic analysis revealed more ETR homologs in various additional lineages within the eukaryotic domain [11]. An ETR homolog was discovered by browsing the genome of Capsaspora owczarzaki (Fig. 1C). This species is representative of the Mesomycetozoa clade, the closest known unicellular group relative of animals. It is now accepted that animals do not possess archetypal histidine kinases, and by extension, lack ETRs. It is thus intriguing to observe that ancestors of animals have developed ethylene signaling pathways to regulate cellular processes, and this was dropped early during the evolution of animals towards multicellularity. Another striking fact is that ETRs were also found in free living amoebae (Acanthamoeba and Balamuthia sp.) (Fig. 1C), but not in obligate parasitic or social (i.e. multicellular) amoebae. As suggested for Mesomycetozoa, it is thus possible that ancestral amoebae developed ethylene sensing for cell-tocell communication, but lost this ETR-mediated transduction system during the path of evolution of these protists. Finally, it is highly likely that ETRs are even more widespread since further genome analysis revealed the presence of candidate genes in Stramenopiles, notably in the oleaginous diatom Fistulifera solaris (Fig. 1C), in the free-living pseudofungus Hyphochytrium catenoides, in many filamentous marine protists belonging to the Labyrinthulomycetes family, but also in two Alveolates associated to coral reefs, i.e. the zooxanthellae Symbiodinium microadriaticum (Fig. 1C) and the Chromerida Vitrella brassicaformis (Fig. 1C). Beyond all these recent observations, the 
strong structural diversity of EtBD-containing proteins in non-plant organisms, as observed in bacteria, teaches us that eukaryotic ETRs may have a large range of biochemical outputs for intracellular ethylene signaling.

\section{Concluding remarks}

In sum, these recent discoveries provide evidence that ethylene sensing, through receptors that are more or less structurally close to the originally described plant histidine kinase ETRs [3], broadly occurs in various microbial lineages. Although these preliminary but noteworthy findings must be explored in more depth and must be strengthened by functional validation, a number of questions arise out of these considerations. One is to determine the role of ethylene and signaling pathways in microbes containing ETRs. It is likely that they are important for responses to environmental conditions or potentially in interspecies communication. A second is, with the exception of plants, why are ETRs predominantly found sporadically in microbial lineages? The appearance of ETRs in cyanobacteria and other bacteria suggests that ETRs were originally developed in ancestral prokaryotes, more than one billion years ago. ETRs were then acquired by several eukaryotic lineages likely via lateral gene transfer events including (i) the endosymbiosis of the cyanobacterium-like ancestor which resulted in plastid formation, (i) bacterial phagocytosis, (ii) and exchanges with large DNA viruses $[4,11]$. Contrary to land plants which have retained and expanded histidine kinase-like ETRs during the evolution for their developmental programs, the other eukaryotic lineages have progressively lost these canonical ethylene-sensing proteins [11]. It is also curious that no typical ETR genes are detected in the genomes of some filamentous fungi (Ascomycota) or multicellular amoebae (Dictyostelids) that are known to sense ethylene for regulating various processes $[9,12]$. This raises the exciting possibility that they possess atypical ETRs that remain hitherto unknown, and thus represents a new challenge to identify.

The recent description of ETR homologs in diverse prokaryotic and eukaryotic lineages sheds new light on the dissemination and evolution of the ethylene sensing pathway in microorganisms. However, tremendous effort is still needed to functionally characterize these putative ETRs and to decipher their physiological roles using complementary biochemical, genetic and modeling approaches.

\section{Acknowledgments}

Funding was provided by the Agence Nationale de la Recherche (program ANR-PRCE Mycormones) to Nicolas Papon and the US National Science Foundation (MCB-1517032) to Brad Binder.

\section{References}

1. North, J.A. et al. (2017) Microbial pathway for anaerobic 5'-methylthioadenosine metabolism coupled to ethylene formation. Proc. Natl. Acad. Sci USA. 114, E10455-E10464

2. Abeles, F., Morgan, P., Saltveit, M.J. (1992) Ethylene in plant biology. Ed 2. Academic Press, San Diego

3. Chang, C., Kwok, S.F., Bleecker, A.B., Meyerowitz, E.M. 1993) Arabidopsis ethylene-response gene ETR1: similarity of product to two-component regulators. Science 262, 539-544

4. Schaller, G.E., Shiu, S.H., Armitage, J.P. (2011) Two-component systems and their co-option for eukaryotic signal transduction. Curr Biol. 2011 21, R320-30

5. Ju, C. et al. (2015) Conservation of ethylene as a plant hormone over 450 million years of evolution. Nat. Plants. 1, 14004

6. Rodríguez, F.I. et al. (1999) A copper cofactor for the ethylene receptor ETR1 from Arabidopsis. Science 283, 996-998

7. Lacey, R.F. and Binder, B.M. (2016) Ethylene regulates the physiology of the cyanobacterium Synechocystis sp. PCC 6803 via an ethylene receptor. Plant Physiol. 171, 2798-2809

8. Song, J.Y. et al. (2011) Near-UV cyanobacteriochrome signaling system elicits negative phototaxis in the cyanobacterium Synechocystis sp. PCC 6803. Proc. Natl. Acad. Sci. USA 108, 10780-10785.

9. Wang, W. et al. (2006) Identification of important regions for ethylene binding and signaling in the transmembrane domain of the ETR1 ethylene receptor of Arabidopsis. Plant Cell. 18, 3429-3442

10. Hérivaux, A. et al. (2017) The identification of phytohormone receptor homologs in early diverging fungi suggests a role for plant sensing in land colonization by fungi. MBio. 8, pii: e01739-16

11. Kabbara, S. et al. (2018) Diversity and evolution of sensor histidine kinases in eukaryotes. Genome Biol. Evol. DOI: $10.1093 /$ gbe/evy213.

12. Amagai, A. (2011) Ethylene as a potent inducer of sexual development. Dev. Growth Differ. 53, 617-623 


\section{Figure legend}

Fig. 1 Ethylene signaling pathways in higher plants and cyanobacteria and identification of ethylene receptor (ETR) homologs in various lineages. (A) Ethylene signaling pathways in the higher plant Arabidopsis. ETR1 is related to the histidine kinase superfamily and is localized in the endoplasmic reticulum membrane. Upon binding to the ETR dimer, ethylene negatively regulates a cell signaling pathway involving downstream mediators including the CTR1 Raf-like kinase, the transmembrane protein EIN2, and the EIN3/EIL family of transcription factors. (B) Ethylene signaling in the cyanobacterium Synechocystis sp. Ethylene negatively regulates the ETR-like protein slr1212 which putatively signals to a downstream response regulator protein, slr1213. The GAF domain binds a chromophore and functions as a light receptor making this a bifunctional receptor. (C) Top: Identification of ETR homologs in various prokaryotic and eukaryotic lineages. The ethylene binding domain (EtBD) located at the N-terminus of the receptors consists of three hydrophobic transmembrane helices harboring seven conserved amino-acids required for ethylene signal perception and transduction. Bottom: An alignment of EtBD sequences from a series of representative ETRs from diverse organisms. The seven conserved amino acids involved in ethylene binding are in pink and marked with blue circles. Abbreviations: ER, endoplasmic reticulum; HK, histidine kinase A subdomain; HA, histidine kinase-like ATPase catalytic subdomain; GAF, cGMP-phosphodiesterase, Adenylyl cyclase, FhIA domain; P, PAS/PAC (Per-period circadian protein; Arnt-Ah receptor nuclear translocator protein; Sim-single minded protein/PAS C-terminus); R, Receiver domain; GGDEF, Diguanylate cyclase domain; EAL, c-di-GMP phosphodiesterase; STYKc, Protein kinase-unclassified specificity; DSRM, Double-stranded RNA binding motif; Athal, Arabidopsis thaliana; M. thiooxydans, Methylophaga thiooxydans; M. mobilis, Methylotenera mobilis; P. fluorescens, Pseudomonas fluorescens; A. cylindrical, Anabaena cylindrica; Rirre, Rhizophagus irregularis; Cowcz, Capsaspora owczarzaki; Acast, Acanthamoeba castellanii; Fsola, Fistulifera solaris. 

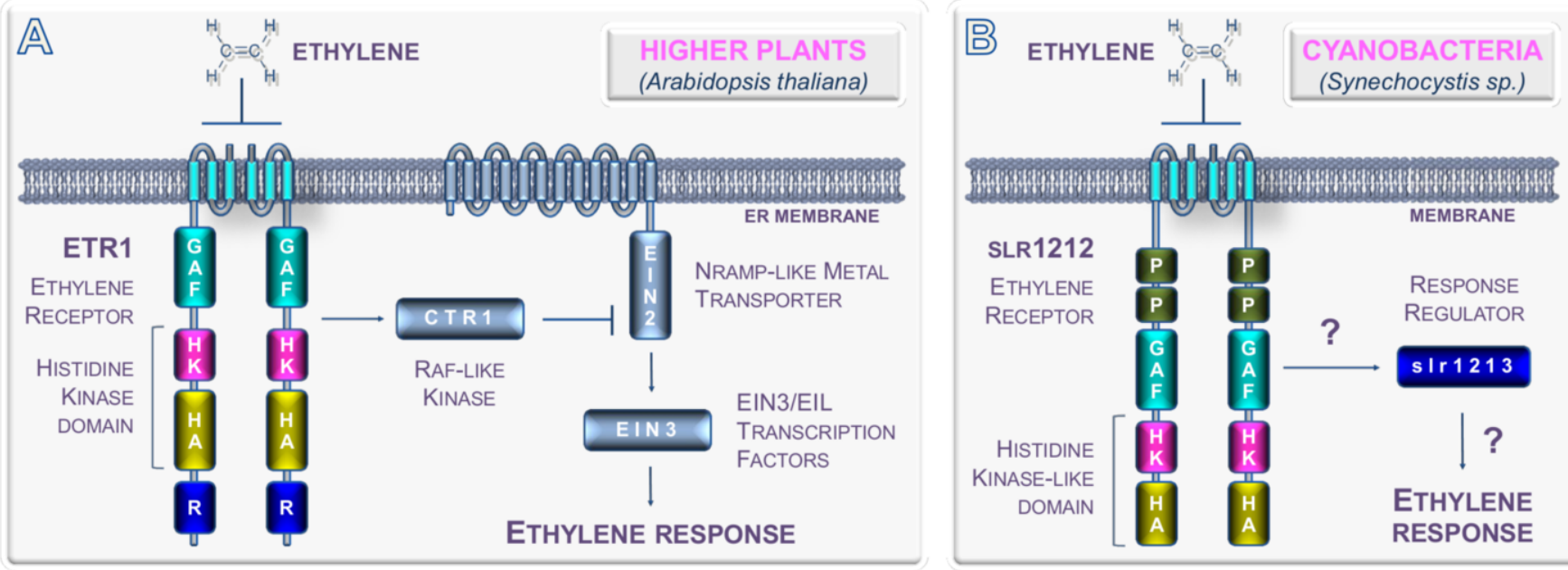

A. thaliana - AthalETR1

M. thiooxydans - LP43_2118

M. mobilis - WP_015831602.1

P. fluorescens - WP_060740083.1

Oscillatoriales JSC-12 - EKQ68367

Cyanothece sp. - WP_012796592.1
A. cylindrica - WP_015216156.1
R. irregularis - RirreHK6

A. macrogynus - AMAG_07095

R. allomycis - RalloHHK2

C. owczarzaki - CowczHK2

A. castellanii - AcastHK35

F. solaris - FsolaHK13

S. microadriaticum - AK812

V. brassicaformis - CEL92723.1
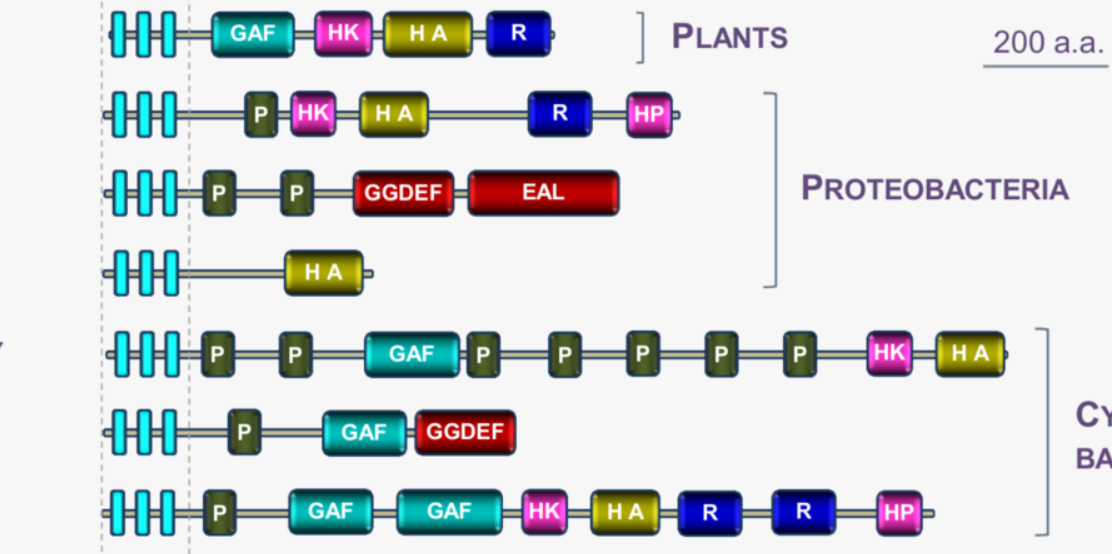

CYANO BACTERIA
Athal ETR1 20-130

Pfluo WP 060740083.1 29-425

Cyano WP_-012796592.1 30-668

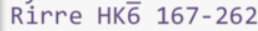

CowCZ HK2 15-112

Acast HK35 69-164

Fsola HK13 1-100

Smicr OLQ02137.1 347-560

Vbras CEL92723.1 41-210
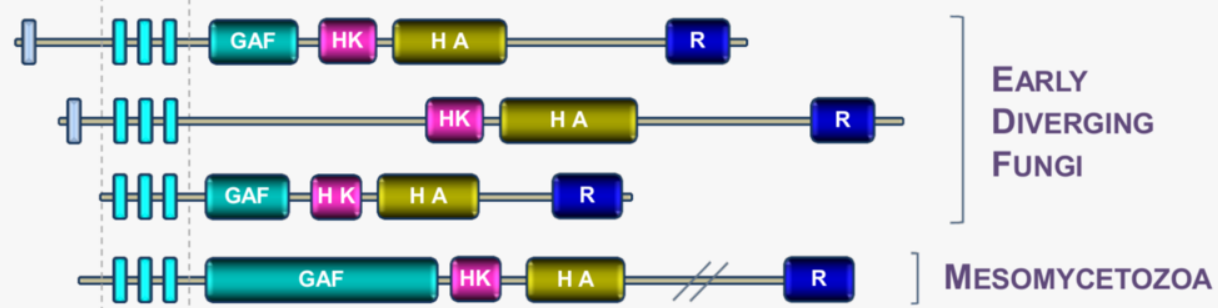

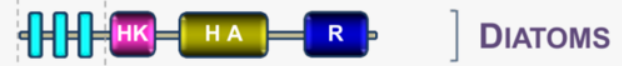

\section{STYKc} DSRM ZOOXANTHELLAE

AMoEBozoA

녱

CHROMERIDA

○

00

YOYISDFFIAIAYFSIPLELIYFV TNVIADSLIALSYVTIPFTLLYFI LHLVSDALITLAYYSIPLILLYFV FICIVDLSIAFAYYTIPFQLMYFM LTMLADLLIALAYFAVPIEIHIFK LLSYSDALIALSYFFIPGAIFTVV -MRHDDLLITLAYFSIPIQLLISL LKPWLDIAICISYISIPLQLIFMA LTIGFDLLTSFAYVSIPIQIFFFV
- 9

WVLVQFGAFIVLCGATHLINLWTF WMLAAFGVFILACGTSHVMEILTI DIFILFSAFILSCGTTHIMNIWTL LVFGLFCAFIILCGTTHIVASWMA VVLVLFESFILACGITHLVHVFMF WTVWMFGAF IVCCGLTHLVSALCI ALIVLFALFIMLCGVGHLLRAFGK LLLFVFALFILCCGFGHGIHAQKA TLGVTFMLFIFFCGTTHFMTALTD
VALVMTTAKVLTAVVSCATALMLVH YYWLMALVKVITAIASVITAILLVR AYWLSGGIKAFTAFISIFTAIQLFT THVLSAVIKVICAIVSLFTAGALTV LMTVMLAAKIACALISVATAIYLIK - -WFNLGMKVVTAGISYATAIAVYK HGDGFELLNGLTAAISVTTALYLIP INVMEAPVHIMTAVISVVATTLLAV AMGLLSFLKGVTCVVSLITAGCLVW 